\title{
A FAST PROCEDURE FOR THE PREPARATION OF BENZIMIDAZOLE DERIVATIVES USING POLYMER- SUPPORTED WITH TRIFLUOROMETHANESULFONIC ACID AS NOVEL AND REUSABLE CATALYST
}

\author{
CHANGIZ KARAMI ${ }^{*}$, KEIVAN GHODRATI ${ }^{*}$, MINA IZADI $^{2}$, AZITA FARROKH ${ }^{1}$, SEDIGHEH JAFARI ${ }^{2}$, \\ MARYAM MAHMOUDIYANI', AND NAHID HAGHNAZARI
}

\author{
${ }^{I}$ Department of Chemistry, Kermanshah Branch, Islamic Azad University, Kermanshah. Iran \\ ${ }^{2}$ Department of Chemistry, Razi University, Kermanshah. Iran
}

(Received: October 8, 2012 - Accepted: April 20, 2013)

\begin{abstract}
A highly selective synthesis of benzimidazoles from the reaction of o-phenylenediamines and aromatic aldehydes in the presence of PVP- trifluoromethanesulfonic acid is reported, and morphological investigation was reported by FT-IR. The remarkable advantages of this method are the simple experimental procedures, shorter reaction times, high yields of product, and non-toxic catalyst. However, the reactions were performed in solvent-free and the catalyst could be reused for several runs.
\end{abstract}

Keywords: Green chemistry; polymer-supported reagents; Benzimidazoles; reusable catalyst

\section{INTRODUCTION}

In the last ten years, supported reagents on polymers have become increasingly applied in organic synthesis ${ }^{1}$, because the reactions are carried out with simple work-up, easy product isolation, and mild reaction conditions ${ }^{2}$. Benzimidazole is a kind of substances which have found practical applications in organic synthesis ${ }^{3}$, and the benzimidazole nucleus are found in a variety of pharmaceuticals as cardiotonic agents, ${ }^{4}$ potential antitumor ${ }^{4}$ poli(ADP-ribose) phosphorilase inhibitors, ${ }^{5}$ Histamine $\mathrm{H} 4$ receptor binders, ${ }^{6}$ antiparasitic, ${ }^{7}$ cardiovascular, ${ }^{8}$ anticancers, ${ }^{4}$ antimicrobials, ${ }^{9}$ and antihypertensives, ${ }^{9}$. Due to the high importance of 2-aryl-1H-benzimidazoles for the preparation of biologically active molecules, their synthesis has been received considerable attention. The condensation of 1,2-phenylendiamines with carboxylic acids or their derivatives in the presence of strong acids such as mineral acids ${ }^{10}$ or polyphosphoric acid ${ }^{11}$ and the thermal or acid-promoted cyclization of $\mathrm{N}-(\mathrm{N}-$ arylbenzimidoyl)-1,4-benzoquinoneimines ${ }^{12}$ was include the methods of benzimidazole synthesis ${ }^{13}$. Direct condensation of o-aryldiamines and aldehydes is not a good synthetic reaction, as it is well known to yield a complex mixture. In this case, the addition of transition metal, namely copper (II) acetate ${ }^{14}$, catalyzed by $\mathrm{Fe}(\mathrm{ClO})_{3}{ }^{15}$, mercury oxide ${ }^{16}$ or lead tetracetate ${ }^{17}$ allow a partial selective synthesis of benzimidazoles. In recent years, solvent-free synthesis of benzimidazoles under microwave irradiation using $\mathrm{Yb}(\mathrm{OTf})_{3}{ }^{18}$, Lithium bromide catalyzed ${ }^{19}$, KSF clay ${ }^{20}, \mathrm{PPA}^{21}$, metal halide supported alumina ${ }^{22}$ and solid support ${ }^{23}$ have been reported. Unfortunately, many of these processes suffer some limitations, such as drastic reaction conditions, low yields, boring work up procedures and co-occurrence of several side reactions. Therefore, the development of a cost effective, safe and environment friendly reagent system is desirable. In addition to, organic synthesis in the absence of a solvent is a powerful tool for the generation of structurally diverse molecules. Solvent-free reactions often, have special selectivity, are easy to set-up and work-up, and are faster, which have aroused great interest ${ }^{24}$. These aspects, coupled with the lower overall costs of running a reaction without solvent and no specially needed equipment, could become a decisive factor in industry. Herein, we wish to disclose a novel protocol for the rapid synthesis of a variety of benzimidazoles using a catalytic amount of PVP-TfOH under solvent-free conditions, and the reaction of this supported reagent is simple work-up, easy product isolation, and mild reaction conditions. However, the reaction was carried out in neat at $70{ }^{\circ} \mathrm{C}$ for 6 minutes, using o-phenylenediamine $(1 \mathrm{mmol})$, aldehyde ( $1.1 \mathrm{mmol})$, and $\mathrm{H}_{2} \mathrm{O}_{2}(30 \%, 3 \mathrm{mmol}, 0.3 \mathrm{~mL})$ in the presence of PVP- trifluoromethanesulfonic acid $(0.2 \mathrm{mg})$ (Scheme 1$)$.

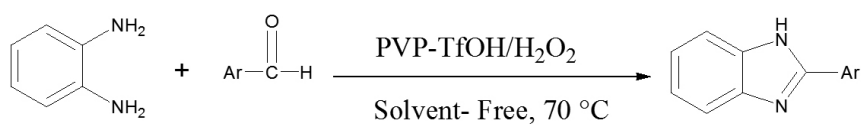

Scheme 1. Synthesis of Benzimidazole Derivatives in the presence of PVP-TfOH.

\section{EXPERIMENTAL}

\section{Materials and Techniques}

All reagents and solvents were purchased from Sigma-Aldrich and Merck, chemical companies. Yields refer to isolated pure products. The benzimidazoles derivatives were characterized by comparison of their spectral (IR, ${ }^{1} \mathrm{HNMR}$ ), TLC and physical data with authentic samples, and the IR spectra of the samples (as $\mathrm{KBr}$ pellets) were recorded using a Rayleigh WQF-510 spectrophotometer in the range of $400-4000 \mathrm{~cm}^{-1}$. Melting points were determined using Electrothermal 9300 Melting Point. ${ }^{1} \mathrm{H}$ NMR and ${ }^{13} \mathrm{CNMR}$ spectra were recorded on Bruker $200 \mathrm{MHz}$ and $50 \mathrm{MHz}$ spectrometer.

Preparation of PVP-Tf 20

A Trifluoromethanesulfonic acid $(\mathrm{TfOH})(2.0 \mathrm{ml})$ was added to poly (4-vinylpyridine) $(2 \mathrm{~g})$, and it was stirred magnetically for $2 \mathrm{~h}$ at room temperature. The suspension was filtered and washed with $\mathrm{CH}_{2} \mathrm{Cl}_{2}(2 \times 5 \mathrm{ml})$ and the poly (4-vinylpyridine)-supported with tifluoromethansulfonic acid ( $\mathrm{PVP}-\mathrm{TfOH})$ was obtained. The activity of this polymer was determined by potentiometric titration with a $0.1 \mathrm{~N}$ solution of $\mathrm{NaOH}$. The activity of polymer was calculated ( $0.1 \mathrm{~g}$ of catalysis equal to $0.08 \mathrm{mmol}$ ).

\section{Typical Procedure for the Preparation of Benzimidazoles}

A mixture of o-phenylenediamine $(1 \mathrm{mmol})$, 4-chlorobenzaldehyde $(1.1$ $\mathrm{mmol})$, and $\mathrm{H}_{2} \mathrm{O}_{2}(30 \%, 3 \mathrm{mmol})$, and PVP- TfOH $(0.2 \mathrm{~g})$ was stirred magnetically for $6 \mathrm{~min}$ at $70{ }^{\circ} \mathrm{C}$, and the progress of the reaction was monitored by TLC. After completion of the reaction, the reaction mixture filtered and washed with $\mathrm{CH}_{2} \mathrm{Cl}_{2}(15 \mathrm{ml})$ there time. If further purification was needed, by recrystallization it was dissolved in $\mathrm{EtOH}(10 \mathrm{~mL})$ and then poured into ice water $(30 \mathrm{~mL})$. The pure solid product was filtered, washed with ice water, and subsequently dried.

2-(4-Chlorophenyl)-1H-benzimidazole (Table 3, entry 1): $\mathrm{mp} 290-293^{\circ} \mathrm{C}$; ${ }^{1} \mathrm{H}-\mathrm{NMR}(200 \mathrm{MHz}, \mathrm{DMSO}-\mathrm{d} 6$ ): $\delta=7.10$ (m, 2H), $7.30(\mathrm{~m}, 2 \mathrm{H}), 7.6(\mathrm{~d}, 2 \mathrm{H}$, $\mathrm{J}=8.4 \mathrm{~Hz}), 8.20(\mathrm{~d}, 2 \mathrm{H}), 12.5(\mathrm{~s}, 1 \mathrm{H}, \mathrm{NH}): 13 \mathrm{C}-\mathrm{NMR}(50 \mathrm{MHz}$, DMSO-d6): $\delta=115.4,123.2,128.6,128.9,129.4,134.3,138.9,152.9$.

\section{RESULTS AND DISCUSSION}

In this study, we became interested to explore a new reagent (PVP-TfOH) for the synthesis of various benzimidazole derivatives, and the PVP-TfOH catalysis was prepared via a reaction of rifluoromethanesulfonic acid with poly (4-vinylpyridine) (Scheme 2).

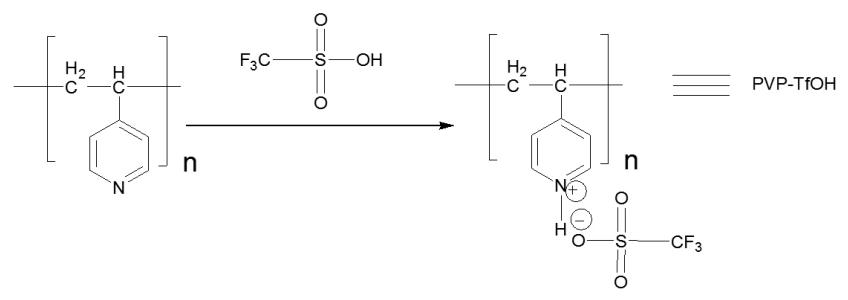

Scheme 2 
The FT-IR spectrum of PVP and the PVP-TfOH catalyst was shown in (Fig 1). The catalyst is solid and solid state IR spectrum was recorded using the $\mathrm{KBr}$ disk technique. The Fig 1a is showed the FT-IR spectrum of PVP, and also the FT-IR spectrums (Fig 1b) is showed the new signals appeared to the signals observed for PVP. These new peaks are assigned to the C-F stretching from 1000 to $1400 \mathrm{~cm}^{-1}$ and sulfonates $\mathrm{S}=\mathrm{O}$ stretching near $1175-1300 \mathrm{~cm}^{-1}$, S-O stretching near $1000-750 \mathrm{~cm}^{-1}$, and broad $\mathrm{OH}$ stretching absorption around 3500 and $2800 \mathrm{~cm}^{-1}$

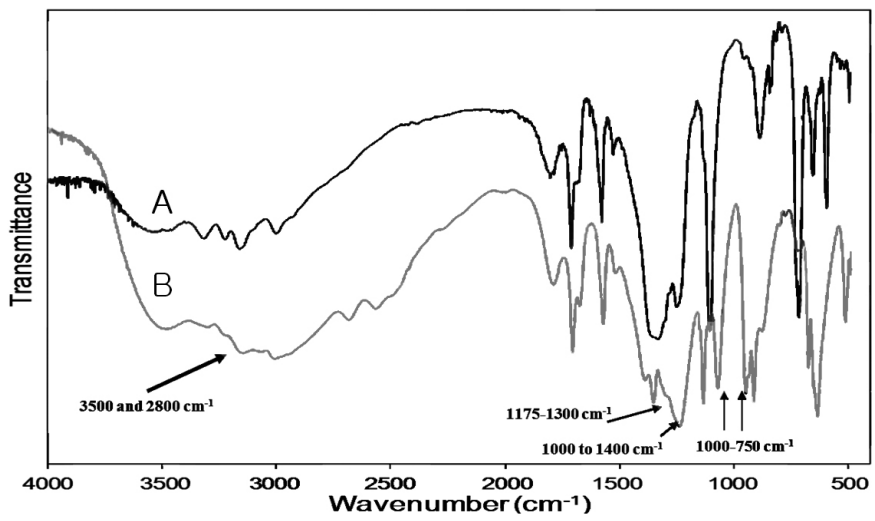

Fig 1. A) FTIR spectrum of poly (4-vinylpyridine) in $\mathrm{KBr}$, and (B) $\mathrm{PVP}+\mathrm{TfOH}$

Initially, a reaction was carried out in neat at $70{ }^{\circ} \mathrm{C}$, using o-phenylenediamine (1 mmol), 4-chlorobenzaldehyde $(1.1 \mathrm{mmol})$, and $\mathrm{H}_{2} \mathrm{O}_{2}(30 \%, 3 \mathrm{mmol})$ in the presence of PVP-TfOH. With this optimistic result in hand, we further probed the best reaction condition by using different amounts of PVP- TfOH. An increase amount of catalyst from $0.1 \mathrm{~g}$ to $0.2 \mathrm{~g}$ not only decreased the reaction time from $9 \mathrm{~min}$ to $6 \mathrm{~min}$ but also increased the product yield from 90 to $95 \%$. This showed that the catalyst concentration plays a major role in optimization of the product yield. Although the use of $0.3 \mathrm{~g}$ of this catalyst permitted the reaction time to be decreased to $5 \mathrm{~min}$, the yield is become persistent. These results indicate that the amount of catalyst is required (Fig.2a).

In the (Scheme 3 ) the suggested mechanism for the preparation of benzimidazoles was shown that the actual oxidant is $\mathrm{H}_{2} \mathrm{O}_{2}$. wherein the absence of $\mathrm{H}_{2} \mathrm{O}_{2}$ resulted in an extremely slow reaction in sufficient for complete product formation even after $15 \mathrm{~h}$. whoever, imine derivative was obtained as only product. Also, different amounts of $\mathrm{H}_{2} \mathrm{O}_{2}$ in conditions as (Tables 3), and the results are depicted in (Fig.2b).

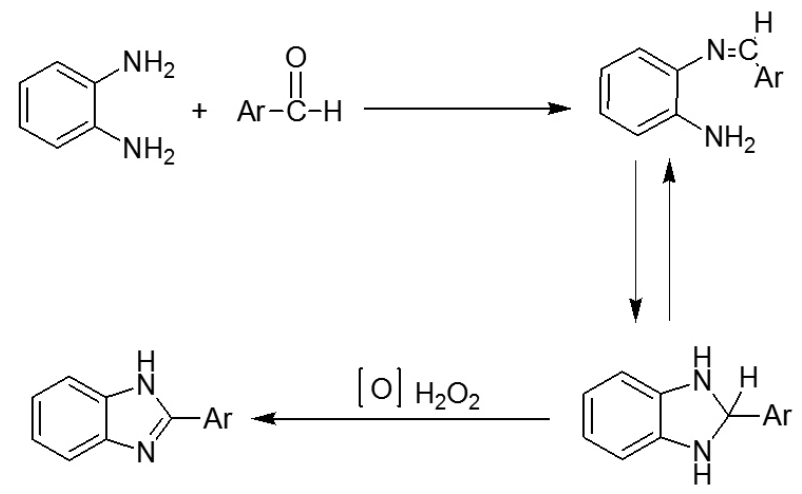

Scheme 3. The proposed mechanism for the preparation of benzimidazoles

To evaluate the effect of reaction temperature, the effect of temperature on the rate of reaction was studied at different temperatures for the preparation of benzimidazoles in the presence of PVP-TfOH system (Table 1). It was observed that the reaction was found to be very slow at room temperature. At $50{ }^{\circ} \mathrm{C}$, the reaction proceeded smoothly and almost the complete conversion of the product was observed. Further increase in temperature to 70,90 and $110{ }^{\circ} \mathrm{C}$ increased the rate of reaction. Therefore, we kept the reaction temperature at 70 ${ }^{\circ} \mathrm{C}$ (giving short reaction time and high yield).
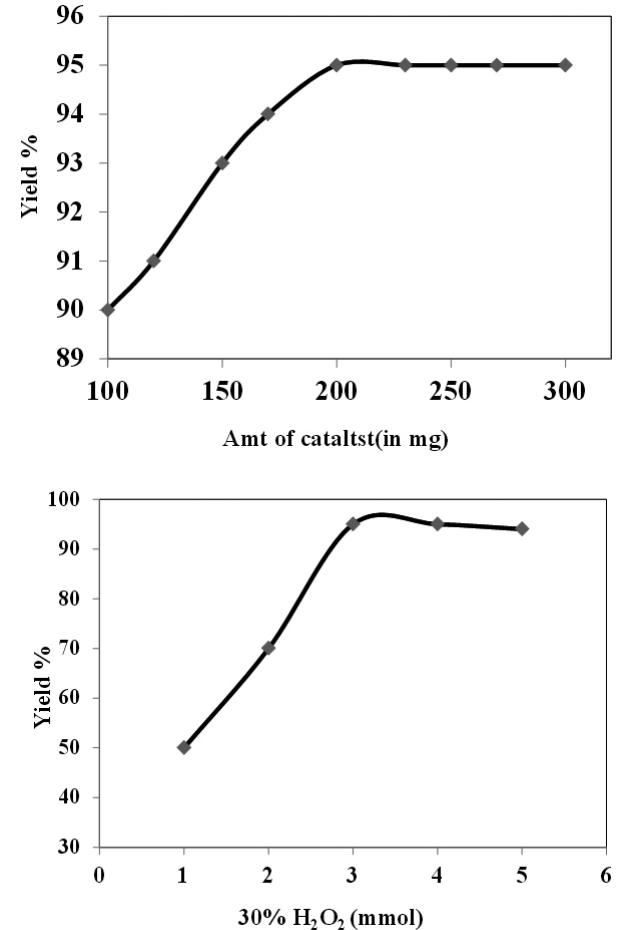

Fig.2. a) Effect of catalyst weight and b) Effect of Amounts of $\mathrm{H}_{2} \mathrm{O}_{2}$ (conditions as Tables 3 ).

Table 1. Effect of temperature for the preparation of 2-(4-chlorophenyl)$1 \mathrm{H}-$ benzo[d]imidazole under solvent-free using PVP-TfOH catalysts as catalyst $(0.2 \mathrm{~g})$.

\begin{tabular}{|c|c|c|c|}
\hline Entry & Temperature $\left({ }^{\circ} \mathbf{C}\right)$ & Time(min) & Yield (\%) \\
\hline 1 & $\mathrm{rt}$ & $2 \mathrm{~h}$ & 60 \\
\hline 2 & 50 & 15 & 95 \\
\hline 3 & 70 & 6 & 95 \\
\hline 4 & 100 & 4 & 95 \\
\hline 5 & 110 & 4 & 96 \\
\hline
\end{tabular}

Certainly, solvent plays a critical role in the reactions; therefore, we decided to investigate the effect of various solvents and select an appropriate condition for the preparation of benzimidazole. Therefore, we screened different solvents such as acetonitrile, ethanol, THF, acetonitrile, water, toluene, and solvent free for the preparation of benzimidazole, as a typical example, the 4-chlorobenzaldehyde and 1,2-phenylendiamine as substrates in the presence of $(0.2 \mathrm{~g})$ catalyst and $\mathrm{H}_{2} \mathrm{O}_{2}(3 \mathrm{mmol})$ in different solvents at $70^{\circ} \mathrm{C}$ (Table 2). Solvent -free was found to be the most efficient for this transformation. The reactions in other solvents required longer reaction time and low yield

Table 2. Reaction of chlorobenzaldehyde, 1,2-phenylendiamine under 6 min conditions.

\begin{tabular}{|c|c|c|}
\hline Entry & Solvent $^{\text {a }}$ & Yield (\%) \\
\hline 1 & Ethyl acetate & 62 \\
\hline 2 & Acetonitrile & 20 \\
\hline 3 & Ethanol & 62 \\
\hline 4 & n-hexane & 10 \\
\hline 5 & $\mathrm{H}_{2} \mathrm{O}$ & 25 \\
\hline 6 & Solvent- Free & 95 \\
\hline 7 & THF & 30 \\
\hline
\end{tabular}

${ }^{\text {a }}$ Refluxed 
J. Chil. Chem. Soc., 58, № 3 (2013)

Table 3. Reaction conditions: o-phenylenediamine ( $1 \mathrm{mmol})$; aldehyde $(1.1 \mathrm{mmol}) ; \mathrm{H}_{2} \mathrm{O}_{2}(30 \%, 3 \mathrm{mmol})$ in the presence of PVP-TfOH $(0.2 \mathrm{~g})$.

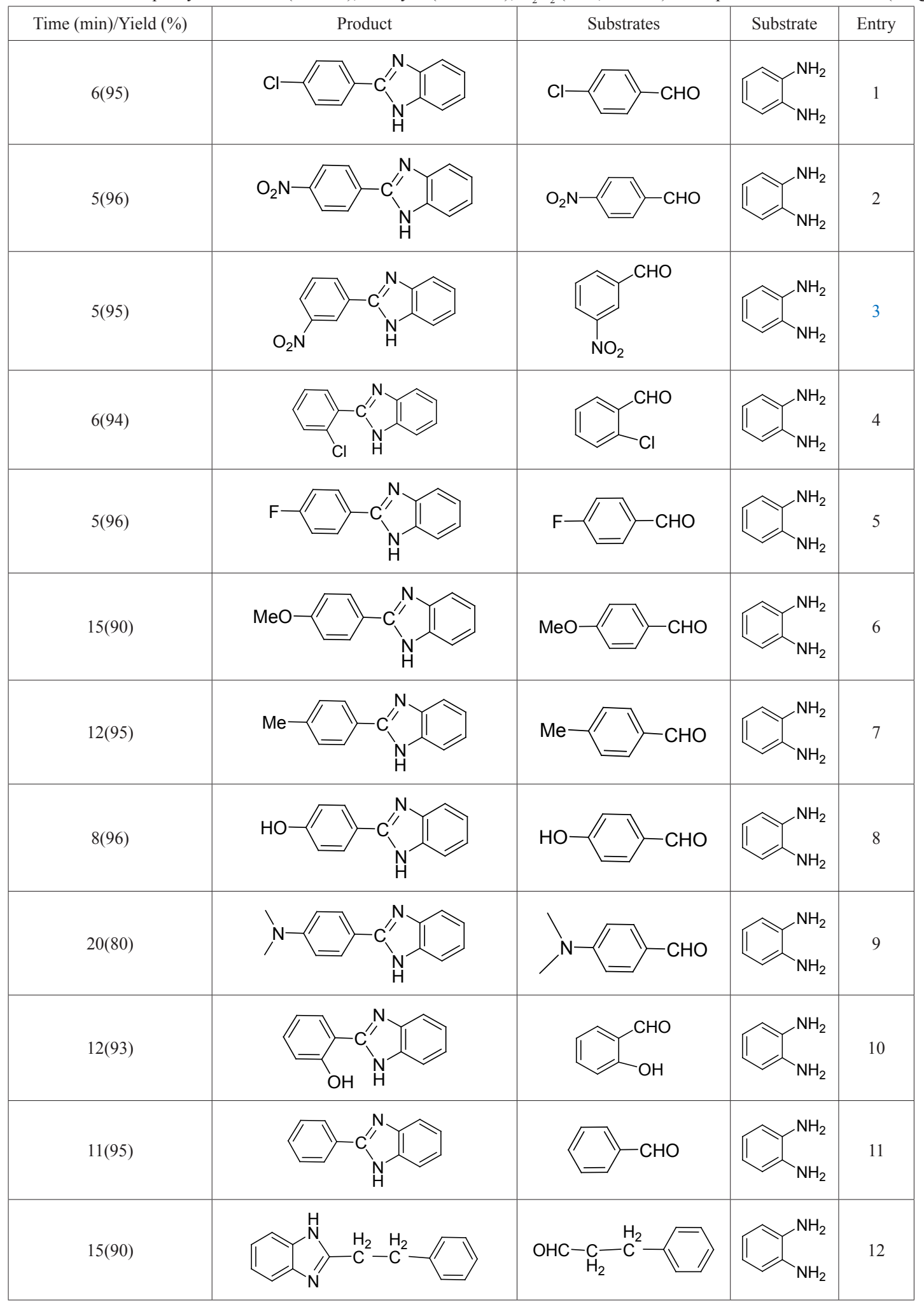

a The products were characterized by comparison of their spectroscopic and physical data with authentic samples synthesized by reported procedures.

${ }^{\mathrm{b}}$ Yields refer to pure isolated products.

The generality of this reaction was examined using several types of aldehydes with o-phenylenediamine under the optimized reaction conditions. In all cases, the reactions gave the corresponding products. In order to study the generality of this procedure, a series of benzimidazoles compounds were synthesized using several types of aldehydes. A ratio of 1,2-phenylendiamine( $1 \mathrm{~mol})$, aryl aldehyde (1.1mol), $\mathrm{H}_{2} \mathrm{O}_{2}(3 \mathrm{mmol}), \mathrm{PVP}-\mathrm{TfOH}(0.2 \mathrm{~g})$ was found to be optimum for the cou- 
pling of aryl aldehydes and 1,2-phenylendiamines and the results are presented in (Table 3). As shown, variety of substituted aromatic aldehydes such as either electron-donating (Table 3, entry 7-11) or electron-withdrawing, substituents (Table 3, entry 2-6) were successfully employed to prepare the corresponding benzimidazole derivatives in excellent yields. In addition, aryl and alkyl aldehydes could also be used for efficient preparation of various heterocyclicbenzimidazoles (Table 3, entry 11 and 12).

The re-use of PVP/ TfOH was investigated in the reaction between 4-chlorobenzaldehyde, o-phenylenediamine $(1 \mathrm{mmol})$, 4-chlorobenzaldehyde $(1.1$ $\mathrm{mmol})$, and $\mathrm{H}_{2} \mathrm{O}_{2}(30 \%, 3 \mathrm{mmol}, 0.3 \mathrm{~mL})$. After completion of the reaction, the reaction mixture was filtered, and the catalyst was recovered after each run, washed three times with acetone, dried in a room temperature prior to use and tested for its activity in the subsequent run and no fresh catalyst was added. The catalyst was tested three times. It was seen that the catalyst displayed very good reusability (Fig. 3).

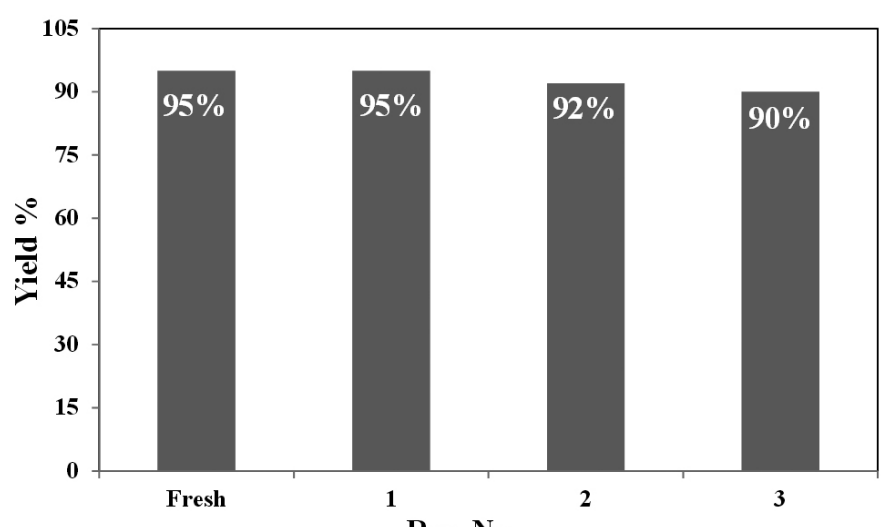

Run No.

Fig. 3, Reusability of the catalyst (conditions as in Tables 3)

\section{CONCLUSIONS}

In summary, we have developed a new polymer-supported by Trifluoromethanesulfonic for the synthesis of benzimidazoles. Our method has several advantages including short reaction times, mild conditions, excellent yields, inexpensive and non-toxic catalyst, simple operation and work-up. Additionally, the protocol does not require volatile and hazardous organic solvents and an additional ultrasound or microwave oven. The elimination of the solvent has obvious environmental benefits with regard to the depletion of solvent waste. Also the catalyst could be successfully recovered at least for three runs without significant loss in activity.

\section{ACKNOWLEDGMENT}

We are thankful to the Islamic Azad university branch of Kermanshah for the partial support for this work

\section{SUPPLEMENTARY MATERIAL:}

Complete experimental procedures and relevant spectra $\left({ }^{1} \mathrm{H} N M R\right.$ and ${ }^{13} \mathrm{C}$ NMR spectra) for some compounds. This material is available in Supporting Information

\section{REFERENCES}

1. (a) M. Adharvana Chari,K. Syamasundar, Catalysis Communications. 6 , 624, (2005) ; (b) A. Ghorbani-Choghamarani,Z. Chenani,S. Mallakpour, Synthetic Communications ${ }^{\circledR}$. 39, 4264, (2009) ; (c) J. Xian,Q. Hua,Z. Jiang,Y. Ma,W. Huang, Langmuir. 28, 6736, (2012)

2. S. J. Shuttleworth,S. Allin,P. K. Sharma, Synthesis-Journal of Synthetic Organic Chemistry. 1217, (1997)

3. Y. Bai,J. Lu,Z. Shi,B. Yang, Synlett. 2001, 0544, (2001)

4. W. A. Denny,G. W. Rewcastle,B. C. Baguley, Journal of Medicinal Chemistry. 33, 814, (1990)

5. A. W. White,N. J. Curtin,B. W. Eastman,B. T. Golding,Z. Hostomsky,S. Kyle,J. Li,K. A. Maegley,D. J. Skalitzky,S. E. Webber,X.-H. Yu,R. J. Griffin, Bioorganic \&amp; Medicinal Chemistry Letters. 14, 2433, (2004)

6. A. Lee-Dutra,K. L. Arienti,D. J. Buzard,M. D. Hack,H. Khatuya,P. J.
Desai,S. Nguyen,R. L. Thurmond,L. Karlsson,J. P. Edwards,J. G. Breitenbucher, Bioorganic \&amp; Medicinal Chemistry Letters. 16, 6043, (2006)

7. R. M. Cedillo-Rivera, O, J. Med. Microbiol. 37, 221, (1992)

8. T. Gungor,A. Fouquet,J. M. Teulon,D. Provost,M. Cazes,A. Cloarec, Journal of Medicinal Chemistry. 35, 4455, (1992)

9. E. S. Seyhan, N.; Nilgun, A.; Noyanalpan, N. Arzneimittel-Forschung. 47, 410, (1997)

10. M. R. I. a. T. B. D. Grimmett, In ComprehensiVe Heterocyclic Chemistry; Katritzky, A. R., Rees, C. W. Eds.; Pergamon: Oxford. 5, 457, (1984)

11. P. N. B. a. C. T. C. Preston, In The Chemistry of Heterocyclic Compounds; Weissberger, A., Taylor, E. C. Eds.;

Wiley: New York. 40, 6, (1981)

12. T. S. Benincori, F, J. Heterocycl. Chem. 25, 1029, (1988)

13. R. R. Nagawade,D. B. Shinde, Chinese Chemical Letters. 17, 453, (2006)

14. R. Weidenhagen, Ber. 69, 2263, (1936)

15. H. A. Oskooie,M. M. Heravi,A. Sadnia,F. K. Behbahani,F. Jannati, Chinese Chemical Letters. 18, 1357, (2007)

16. M. J. P. Jakobson, F. Meyer, Ber. 29, 2682, (1896)

17. J. D. B. F. F. Stevens, J. Chem. So. 2971, (1949)

18. J. S. L. Wang, H. Tian, Et Al, Synth. Commun. 34, 4265, (2004)

19. D. V. Dekhane,S. S. Pawar,S. V. Gupta,M. S. Shingare,S. N. Thore, Chinese Chemical Letters. 21, 519, (2010)

20. A. P. A. Loupy, J. Hamelin, Et Al, Synthesis. 9, 1213, (1998)

21. B. Y. J. Lu, Y. Bai, Synth. Commun. 32, 3703, (2002)

22. V. V. V. N. S. R. G. V. Reddy, B. Narsaiah, Et Al, Synth. Commun. 32 2467, (2002)

23. I. B. G. Penieres, G. Lopez, Et Al, Synth. Commun. 30, 2191, (2000)

24. K. Tanaka,F. Toda, Chemical Reviews. 100, 1025, (2000) 